\title{
Essential Oil Composition of Lavandin (Lavandula $x$ intermedia) cultivated in Bismil-Turkey
}

\author{
${ }^{1}$ Mustafa Abdullah Yilmaz \\ ${ }^{1}$ Dicle University, Faculty of Pharmacy, Department of Pharmaceutical Chemistry, Diyarbakir, Turkey
}

\begin{abstract}
:
The goal of this study was to investigate the essential oil compositions of different parts (stem, leaf, flower and mixture) of Lavandula x intermedia in Bismil-Diyarbakır,Turkey. The chemical composition of essential oils obtained by hydrodistillation from fresh Lavandin samples were analyzed using gas chromatography-mass spectrometry (GC/MS). The results indicate the major components of the studied parts of lavandin was; linalool (24.97-2.52-43.86-39.43 \%), linalyl acetate (3.,4-0.29-9.37-15.76 \%), eucalyptol (33.81-43.81-18.47-12.08\%), camphor (13.12-15.91-8.72-9.21\%), endo-borneol (2.03-5.180.68-1.24 \%) and alpha-terpineol (2.84-2.47-1.28-3.86\%) in essential oils of stem, leaf, flower and mixture parts of fresh lavandin respectively. It was understood that linalool and linalyl acetate level were the highest in flower and mix parts while eucalyptol, camphor and endo-borneol levels were the highest in stem and leaf parts of the plant.
\end{abstract}

Key words: Dust, aas, icpoes, disposal tank, urbanization (should be a maximum of 5 keywords)

\section{Introduction}

Medicinal and aromatic plants have been of great importance and used for variety of purposes since ancient times. Nowadays, they have been economically important crops for essential oil production globally (Bajalan et al., 2016). Recently, essential oils of these plants have beeen commercially popular due to their impression as a "well-being" life style (Yang et al., 2010).

The industrial cultivation and production of Lavandula angustifolia Mill. and Lavandula $x$ intermedia as medicinal and aromatic plants have been rapidly raised during the last years and the World's interest for Lavandula essential oil is still increasing. Therefore, detailed analyses of produced essential oils to figure out their quality and quantity are highly important for the selection of industrial usage. The trade value of essential oil export in the world is approximately 1.90-2.00 billion dollars and about 50 million dollars of this currency belong to Lavandula essential oil (Gökdoğan, 2016).

Essential oils, obtained from medicinal and aromatic plants by using various methods such as steam distillation, hydro distillation, cold press or extraction, are mixtures of various chemical constituents including terpenes, alcohols, aldehydes, phenols and esters, which may produce significant fragrances (Grassmann and Elstner, 2003; Ali et al., 2015).

Lavandula is a plant which is fairly resistant to drought and temperature (Weiss, 1997). There are 39 Lavandula species (Lavandula sp.) which are mostly of Mediterranean origin. However, there are three important species within the genus producing lavender (Lavandula angustifolia Mill. $=\mathrm{L}$. 
officinalis L. = L. vera DC), lavandin (Lavandula intermedia Emeric ex Loisel. = L. hybrida L.) and Spike lavender (Lavandula spica = L. latifolia Medik.) (Tucker, 1985). Lavender essential oil is higher quality than that produced by lavandins because lavender essential oil has lower camphor content than lavandin cultivars. Therefore, lavender essential oils are used in perfumes and aromatherapy, and lavandin essential oils are used in soap, detergents and cosmetics products (LisBalchin, 2002). However, lavandin essential oil yield is higher than that from lavenders (Beetham and Entwistle, 1982). Lavandula sp. is one of important medicinal and aromatic plants that are cultivated in Turkey. Isparta is the most significant lavandin (L.x intermedia Super A) production area of Turkey. In Isparta, lavandin is cultivated on an area of 250 hectares, with an annual production of 2.5 tons (Kara and Baydar, 2011).

Many Lavandula species have essential oils with aromatic and medicinal properties that able use in the cosmetic, pharmaceutical and food industries (Torras-Claveria etal.,2007) but specially three of these species are important with their high commercial value: Lavender (Lavandula angustifolia Mill. syn. L. officinalis Chaix ex Vill syn. L. vera DC syn. L. spica (true lavender, fine lavender or English lavender), Lavandin (Lavandula intermedia Emeric ex Loisel syn. L. hybrid, a hybrid of L. angustifolia and L. latifolia), and Spike lavender (Lavandula latifolia Medicus) (LesageMeessen et al., 2015). The world production of lavender oil is approximately 200 tons per year. Bulgaria, UK and France are dominating the lavender essential oil production. The world production of lavandin oil is about 1200 tons per year with a rate of $90 \%$ representing by France (Karapandzova et al., 2012).

The aim of this study was to determine the essential oil composition of different parts of (stem, leaf, flower and mix) Lavandula $x$ intermedia Emeric cultivated in Bismil-Diyarbakır, Turkey by using GC-MS and headspace GC-MS techniques.

\section{Materials and Method}

\subsection{Plant material}

Aerial parts of the plant material (Lavandula $x$ intermedia Emeric) cultivar was collected from Bismil-Diyarbakır, Turkey in September 2018 by a local farmer when the crop was in full of blossom. The plant materials were studied fresh.

\subsection{Isolation of the essential oil}

Aerial parts of freshly harvested plants were separated into parts (stem, leaf, flower and their mixture) and immediately subjected to hydrodistillation in a Clevenger's apparatus for $2 \mathrm{~h}$ to extract the essential oil. The oil was dried over anhydrous sodium sulphate and stored in a refrigerator at $4{ }^{\circ} \mathrm{C}$ prior to analysis.

\subsection{Gas chromatography-Mass spectrometry (GC-MS) analysis}

GC/MS analyses were carried out using an Agilent 7890N Gas Chromatograph equipped with a split/splitless injector, a HP-5MS capillary column $(30 \mathrm{~m} \times 0.25 \mathrm{~mm} \times 0.25 \mu \mathrm{m})$ and coupled with 
an Agilent 5977B MS Detector, operating in the electron impact (EI) mode at $70 \mathrm{eV}$. Transfer line temperature was set at $250{ }^{\circ} \mathrm{C}$. The carrier gas was $\mathrm{He}(1 \mathrm{~mL} / \mathrm{min}$ and $20 \mathrm{psi})$, and the oven temperature was programmed from $60^{\circ} \mathrm{C}$ to $240{ }^{\circ} \mathrm{C}$ at a rate of $3{ }^{\circ} \mathrm{C} / \mathrm{min}$. The injected volume was $1 \mu \mathrm{L}$ and the split ratio $25: 1$. The identification of the compounds was based on the comparison of their retention times (RT) and mass spectra with those from the NIST and Wiley 2008 libraries. Relative percentages of compounds were calculated based on the peak areas from their GC-MS chromatograms.

\section{Results and Discussion}

\subsection{Chemical Composition of the Essential Oil}

Table 1. Essential oil composition (\%) in fresh stem, leas, flower and mixture of lavandin cultivar (FLS: Fresh lavender stem, FLL: Fresh lavender leaf, FLF: Fresh lavender flower, FLM: Fresh lavender mixed parts)

\begin{tabular}{|l|l|l|l|l|l|l|}
\hline & & & FLS & FLL & FLF & FLM \\
\hline$\#$ & R.T. & Name & Area (\%) & Area (\%) & Area (\%) & Area (\%) \\
\hline 1 & 5.38 & alpha-Pinene & 0.95 & 2.65 & 0.71 & 0.39 \\
\hline 2 & 5.77 & Camphene & 0.42 & 1.22 & 0.44 & 0.23 \\
\hline 3 & 6.42 & $4(10)-$ Thujene (Sabinene) & 0.56 & 1.65 & 0.43 & 0.28 \\
\hline 4 & 6.53 & Beta-Pinene & 1.41 & 3.45 & 1.12 & 0.67 \\
\hline 5 & 6.76 & 3-Octanone & 0.25 & 0.27 & 1.53 & 0.76 \\
\hline 6 & 6.90 & Beta-Myrcene & 1.02 & 2.18 & 1.46 & 0.82 \\
\hline 7 & 7.01 & 3-Octanol & - & - & 0.28 & - \\
\hline 8 & 7.34 & alpha-Phellandrene & - & 0.35 & - & - \\
\hline 9 & 7.53 & 3-Carene & 0.50 & 1.75 & 0.84 & 0.50 \\
\hline 10 & 7.74 & alpha-Terpinene & - & - & 0.13 & - \\
\hline 11 & 8.00 & p-Cymene & 0.24 & 0.62 & - & - \\
\hline 12 & 8.15 & D-limonene & 4.04 & - & 1.59 & 1.39 \\
\hline 13 & 8.23 & Eucalyptol (1,8-cineole) & $\mathbf{3 3 . 8 1}$ & $\mathbf{4 3 . 8 1}$ & $\mathbf{1 8 . 4 7}$ & $\mathbf{1 2 . 0 8}$ \\
\hline 14 & 8.43 & trans-Beta-Ocimene & 0.41 & 0.51 & 1.16 & 0.75 \\
\hline 15 & 8.80 & cis-Beta-Ocimene & 0.55 & 0.32 & 2.15 & 1.42 \\
\hline 16 & 9.2 & gamma-Terpinene & - & 0.31 & - & - \\
\hline 17 & 9.50 & cis-4-Thujanol & 0.35 & 0.76 & - & - \\
\hline 18 & 9.71 & Linalool oxide & - & - & 0.20 & 0.26 \\
\hline 19 & 10.31 & alpha- Terpinolen & 0.25 & 0.43 & 0.62 & 0.53 \\
\hline 20 & 10.74 & Linalool & $\mathbf{2 4 . 9 7}$ & $\mathbf{2 . 5 2}$ & $\mathbf{4 3 . 8 6}$ & $\mathbf{3 9 . 4 3}$ \\
\hline 21 & 12.3 & L-Pinocarveol & - & 0.39 & - & - \\
\hline 22 & 12.54 & Camphor & $\mathbf{1 3 . 1 2}$ & $\mathbf{1 5 . 9 1}$ & $\mathbf{8 . 7 2}$ & $\mathbf{9 . 2 1}$ \\
\hline 23 & 13.3 & Pinocarvone & - & 0.14 & - & - \\
\hline 24 & 13.42 & endo-Borneol & 2.03 & 5.18 & 0.68 & 1.24 \\
\hline 25 & 13.5 & Lavandulol & - & - & 0.33 & 0.71 \\
\hline 26 & 13.93 & Terpinen-4-ol & 0.34 & 0.78 & 0.23 & 0.27 \\
\hline 27 & 14.3 & Cryptone & - & 0.66 & - & 0.23 \\
\hline 28 & 14.49 & alpha-Terpineol & 2.84 & 2.47 & 1.28 & 3.86 \\
\hline 29 & 14.59 & n-Hexyl butanoate & 0.58 & - & 1.40 & 1.32 \\
\hline 30 & 14.8 & 1R)-(-)-Myrtenal & - & 0.33 & - & - \\
\hline 31 & 16.13 & Isobornyl formate & 0.28 & - & - & - \\
\hline 32 & 16.6 & Cuminal & - & 0.43 & - & - \\
\hline 33 & 17.29 & Geraniol & 0.45 & - & - & 0.47 \\
\hline
\end{tabular}




\begin{tabular}{|l|l|l|l|l|l|l|}
34 & 17.38 & Linalyl acetate & $\mathbf{3 . 0 4}$ & $\mathbf{0 . 2 9}$ & $\mathbf{9 . 3 7}$ & $\mathbf{1 5 . 7 6}$ \\
\hline 35 & 18.94 & Lavandulol acetate & 0.95 & 0.86 & 1.38 & 2.61 \\
\hline 36 & 20.7 & Hexyl (E)-2-methylbut-2-enoate & - & - & - & 0.31 \\
\hline 37 & 22.17 & Nerol acetate & 0.27 & - & - & 0.64 \\
\hline 38 & 23.01 & Geranyl acetate & 0.48 & - & 0.30 & 1.15 \\
\hline 39 & 24.1 & alpha-Gurjunene & - & 0.46 & - & - \\
\hline 40 & 24.49 & Caryophyllene & 0.68 & 1.82 & 0.44 & 0.62 \\
\hline 41 & 28.22 & bis(2-Ethylhexyl) ether & 0.49 & - & - & - \\
\hline 42 & 28.49 & gamma-Cadinene & 0.47 & 1.45 & - & - \\
\hline 43 & 31.28 & Caryophyllene oxide & 0.31 & 0.82 & - & - \\
\hline 44 & 33.56 & Epicubenol & 1.18 & 2.51 & - & - \\
\hline 45 & 35.22 & ALPHA-BISABOLOL & 0.43 & - & - & 1.01 \\
\hline 46 & 35.46 & Shyobunol & 0.50 & 0.91 & - & - \\
\hline & & TOTAL & 98.21 & 98.21 & 99.10 & 98.88 \\
\hline
\end{tabular}

Essential oil composition obtained by GC-MS in stem, leaf, flower and mixture parts of lavandin cultivar were shown in Table 1. The major constituents were determined as linalool (24.97-2.5243.86-39.43 \%), linalyl acetate (3.,4-0.29-9.37-15.76 \%), eucalyptol (33.81-43.81-18.47-12.08\%), camphor (13.12-15.91-8.72-9.21\%), endo-borneol (2.03-5.18-0.68-1.24\%) and alpha-terpineol (2.84-2.47-1.28-3.86\%) in essential oils of stem, leaf, flower and mixture parts of fresh lavandin respectively. The highest linalool content was found in flower $(43.86 \%)$ while the lowest linalool content was obtained from leaf part of the fresh lavender $(2.52 \%)$. The mixture of all parts contained the highest linalyl acetate $(15.76 \%)$ and the leaf part contained the lowest linalyl acetate $(0.29 \%)$. Eucalyptol level was the highest in leaf part $(43.81 \%)$ and lowest in the mixture of all parts $(12.08 \%)$. As we can see from the results, flower part $(8.72 \%)$ contained the lowest camphor level while the leaf part $(15.91 \%)$ contained the highest level.

Previous studies showed that the ranges of linalool, linalyl acetate and camphor in essential oil of Lavandula $x$ intermedia are 34.8-43.3 \%, 4.35-42.5\% and 7.27-12.5\% respectively (Kara and Baydar, 2013).

\section{Conclusions}

The chemical composition of essential oils obtained by hydrodistillation from fresh Lavandin samples were analyzed using gas chromatography-mass spectrometry (GC/MS). The results indicate the major components of the studied parts of lavandin were; linalool (24.97-2.52-43.86$39.43 \%)$, linalyl acetate (3.,4-0.29-9.37-15.76\%), eucalyptol (33.81-43.81-18.47-12.08\%), camphor (13.12-15.91-8.72-9.21\%), endo-borneol (2.03-5.18-0.68-1.24\%) and alpha-terpineol (2.84-2.47-1.28-3.86\%) in essential oils of stem, leaf, flower and mixture parts of fresh lavandin respectively. It was understood that linalool and linalyl acetate level were the highest in flower and mix parts while eucalyptol, camphor and endo-borneol levels were the highest in stem and leaf parts of the plant.

\section{Acknowledgements}

The author gratefully acknowledge and thank to Suat Daşkın and the farmers for their efforts in collecting and supplying the plant material. 


\section{References}

Bajalan, I., Mohammadi, M., Alaei, M., Pirbalouti, A.G., 2016. Total phenolic and flavonoid contents and antioxidant activity of extracts from different populations of lavandin. Ind. Crops Prod. 87, 255-260. http://dx.doi.org/10.1016/j.indcrop.2016. 04.059.

Yang, S.-A., Jeon, S.-K., Lee, E.-J., Shim, C.-H., Lee, I.-S., 2010. Comparative study of the chemical composition and antioxidant activity of six essential oils and their components. Nat. Prod. Res. 24, 140-151. http://dx.doi.org/10.1080/ 14786410802496598.

Gökdoğan, O., 2016. Determination of input-output energy and economic analysis of lavender productionin Turkey.Int.J.Agric.Biol.Eng.9,154-161.http://dx.doi.org/ 10.3965/j.ijabe.20160903.1774.

Grassmann, J., Elstner, E.F., 2003. Essential oils/Prorpierties and uses. Encicl. Food Sci. Nutr. 2177-2184. http://dx.doi.org/10.1007/BF02850093.

Ali, B., Al-Wabel, N.A., Shams, S., Ahamad, A., Khan, S.A., Anwar, F., 2015. Essential oils used in aromatherapy: a systemic review. Asian Pac. J. Trop. Biomed. 5, 601-611. http://dx.doi.org/10.1016/j.apjtb.2015.05.007.

Weiss, E.A., 1997. Essential Oil Crops. CAB International, New York, USA.

Lis-Balchin M., S. Hart, 1999. Studies on the mode of the action of the essential oil of lavender (Lavandula angustifolia Miller). Phytother Res. 13, 540-542.

Beetham, J., T. Entwistle, 1982. The Cultivated Lavenders. Royal Botanic Gardens, Melbourne.

Kara, N., H. Baydar, 2011. Essential oil characteristics of lavandins (Lavandula x intermedia emeric ex loisel.) of Isparta province, kuyucak district, where lavender production center of Turkey. Journal of Selcuk Agricultre and Food Sciences 25 (4), 41-45. (in Turkish).

Torras-Claveria, L., Jauregui, O., Bastida, J., Codina, C., Viladomat, F., 2007. Antioxidant activity and phenolic composition of Lavandin (Lavandula x intermedia Emeric ex Loiseleur) waste. J. Agric. Food Chem. 55, 8436-8443.

Lesage-Meessen, L., Bou, M., Sigoillot, J., Faulds, C.B., Lomascolo, A., 2015. Essential oils and distilled straws of lavender and lavandin: a review of current use and potential application in white biotechnology. App. Microbiol. Biotechnol. 99, 3375-3385. http://dx.doi.org/10.1007/s00253-015-6511-7.

Karapandzova, M., Cvetkovikj, I., Stefkov, G., Stoimenov, V., Crvenov, M., Kulevanova, S., 2012. The influence of duration of the distillation of fresh and dried flowers on the essential oil composition of lavandin cultivated in Republic of Macedonia. Maced Pharm. Bull. 58, 31-38. 
Kara, N., Baydar, H., 2013. determination of lavender and lavandin cultivars (lavandula sp.) containing high quality essential oil in Isparta, Turkey. Turkish Journal of Field Crops. 18(1), 5865 . 